\title{
Crystal structure of hexabarium pentamagnesium trilithium dodecagermanide, $\mathrm{Ba}_{6} \mathrm{Mg}_{4.9} \mathrm{Li}_{3.1} \mathrm{Ge}_{12}$
}

\author{
F. Zürcher and R. Nesper* \\ ETH Zürich, Laboratorium für Anorganische Chemie, Universitätstraße 6. CH-8092 Zürich. Switzerland
}

Received August 26. 2001, CSD-No. 409572

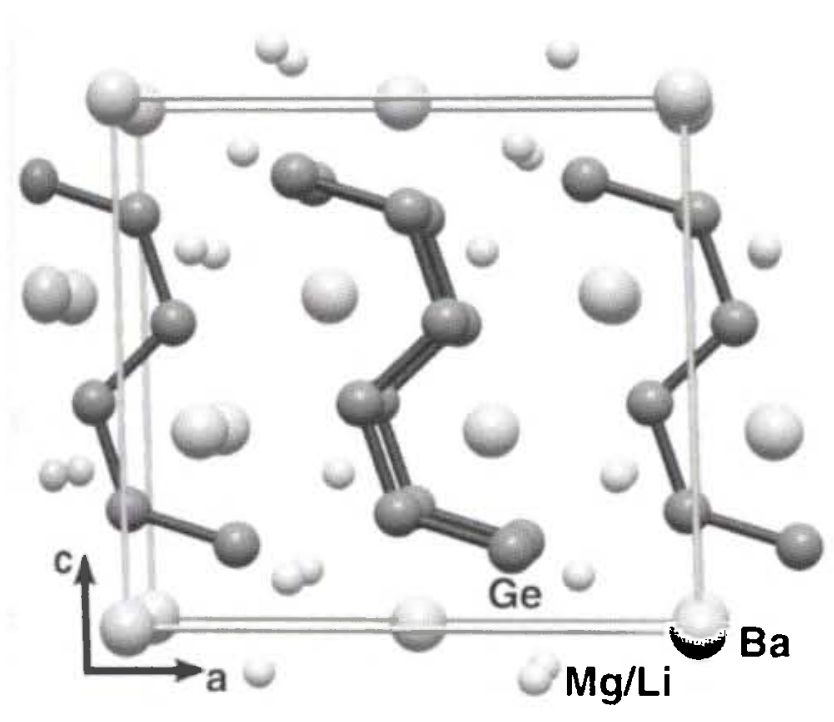

Abstract

$\mathrm{Ba}_{6} \mathrm{Ge}_{12} \mathrm{Li}_{3.1} \mathrm{Mg}_{4.9}$, monoclinic, $C 12 / m 1$ (No. 12), $a=12.320(6) \AA$, $b=4.626(2) \AA, c=11.499(6) \AA, \beta=91.9(1)^{\circ}, V=655.0 \AA^{3}$, $Z=1, R_{\mathrm{gt}}(F)=0.020, w R_{\mathrm{all}}\left(F^{2}\right)=0.042, T=298 \mathrm{~K}$.

\section{Source of material}

$\mathrm{Ba}_{6} \mathrm{Mg}_{4.9} \mathrm{Li}_{3.1} \mathrm{Ge}_{12}$ is prepared by heating the stoichiometric mixture of the elements at $1273 \mathrm{~K}$ (Id, cooling down within $5 \mathrm{~h}$ ). The title compound forms grey-black, rod-like crystals with a metallic lustre. It is exceptionally air and moisture sensitive.

The $M(1)$ and $M(2)$ sites are occupied by different amounts of lithium and magnesium. The corresponding occupancy factors are also refined.

\begin{abstract}
Discussion
$\mathrm{Ba}_{6} \mathrm{Mg}_{4.9} \mathrm{Li}_{3.1} \mathrm{Ge}_{12}$ crystallises with the $\mathrm{Ba}_{6} \mathrm{Mg}_{5.3} \mathrm{Li}_{2.7} \mathrm{Si}_{12}$ structure type [1]. The Zintl anion is a $\mathrm{Ge}_{6}$ cis-trans chain. This compound contains the same building blocks as other Zintl phases with linear Zintl anions [2-4]. Each bond is coordinated by four planar metal atoms. The bond has a trans conformation when it is coordinated by four barium atoms and a cis conformation when beside barium also magnesium and lithium are present in the metal square. The terminal germanium atoms are always coordinated by magnesium and lithium. Lacking of 3.1 electrons, $\mathrm{Ba}_{6} \mathrm{Mg}_{4.9} \mathrm{Li}_{3.1} \mathrm{Ge}_{12}$ does not follow the simple Zintl-Klemm concept. The states at the Fermi level are centred on the $\mathrm{Ge}_{6}$ chain and have a $\pi$ character. The Zintl anions are ecliptically stacked with a distance of $4.6 \AA$. These are the two conditions for intermolecular $\pi$ interactions along the stacking direction, which may cause a one-dimensional metallic conductivity [3-5].
\end{abstract}

Table 1. Data collection and handling.

Crystal:

Wavelength:

$\mu$ :

Diffractometer, scan mode:

$20_{\max }$ :

$N(h k l)_{\text {measured, }} N(h k l)_{\text {unique: }}$

Criterion for $I_{\text {obs }}, N(h k l)_{g l}$ :

$N(\text { param })_{\text {refined: }}$

Programs: black rod, size $0.10 \times 0.10 \times 0.15 \mathrm{~mm}$

Mo $K_{\alpha}$ radiation $(0.71073 \AA)$

$224.86 \mathrm{~cm}^{-1}$

Stoe STADI $4, \omega / \theta$

$60^{\circ}$

4274, 1069

$I_{\mathrm{obs}}>2 \sigma\left(I_{\mathrm{obs}}\right), 917$

44

SHELXS-96 [6], SHELXL-96 [7]

COLTURE 3-D [8]

Table 2. Atomic coordinates and displacement parameters (in $\AA^{2}$ ).

\begin{tabular}{lllllllllll}
\hline Alom & Site & $x$ & $y$ & $z$ & $U_{11}$ & $U_{22}$ & $U_{33}$ & $U_{12}$ & $U_{13}$ & $U_{23}$ \\
\hline $\mathrm{Ba}(1)$ & $2 a$ & 0 & 0 & 0 & $0.0179(2)$ & $0.0165(2)$ & $0.0144(2)$ & 0 & $0.0006(1)$ & 0 \\
$\mathrm{Ba}(2)$ & $4 i$ & $0.14031(2)$ & 0 & $0.37122(2)$ & $0.0143(1)$ & $0.0160(1)$ & $0.0143(1)$ & 0 & $0.00126(8)$ & 0 \\
$\mathrm{M}(1)^{a}$ & $4 i$ & $0.1340(2)$ & 0 & $0.7125(3)$ & $0.013(1)$ & $0.017(2)$ & $0.021(2)$ & 0 & $0.001(1)$ & 0 \\
$\mathrm{M}(2)^{b}$ & $4 i$ & $0.2875(1)$ & 0 & $0.0933(2)$ & $0.0144(9)$ & $0.0172(9)$ & $0.0154(9)$ & 0 & $0.0026(6)$ & 0 \\
$\mathrm{Ge}(1)$ & $4 i$ & $0.32076(4)$ & 0 & $0.85088(4)$ & $0.0121(2)$ & $0.0163(2)$ & $0.0154(2)$ & 0 & $0.0020(2)$ & 0 \\
$\mathrm{Ge}(2)$ & $4 i$ & $0.48338(4)$ & 0 & $0.21640(4)$ & $0.0118(2)$ & $0.0195(2)$ & $0.0135(2)$ & 0 & $0.0005(2)$ & 0 \\
$\mathrm{Ge}(3)$ & $4 i$ & $0.42338(4)$ & 0 & $0.42366(4)$ & $0.0140(2)$ & $0.0197(2)$ & $0.0131(2)$ & 0 & $0.0012(1)$ & 0 \\
\hline
\end{tabular}

a: $\mathrm{M}(1)=0.419(9) \mathrm{Mg}+0.581 \mathrm{Li}$

b: $\mathrm{M}(2)=0.809(9) \mathrm{Mg}+0.191 \mathrm{Li}$

\footnotetext{
* Correspondence author (e-mail: nesper@@inorg.chem.ethz.ch)
} 
Acknowledgment. This work was supported by the Swiss National Foundation under project No. 2000-050675.97

\section{References}

1. Wengert, S.; Nesper, R.: Topological Relationships and Building Blocks in Zintl Phases of the Composition $\mathrm{Ba}_{n+1}(\mathrm{Mg}, \mathrm{Li})_{2 n} \mathrm{Si}_{2 n+1}$. Inorg. Chem. 39 (2000) 2861-2865.

2. Currao, A.; Curda, J.: Nesper, R.: Kann man die Arten von Zintl-Anionen steuern? Variationen über das Thema $\mathrm{Si}^{2-}$ im System Sr/Mg/Si. Z. Anorg. Allg. Chem. 622 (1996) 85-94.

3. Wengert, S.: Experimentelle und Theoretische Lösungsansätze zu Grundlegenden Problemen in Zintlverbindungen. Dissertation No. 12070. ETH Zürich, Switzerland 1997.

4. Zürcher, F.: Syntheses, Structures, and Properties of Zintl Phases Formed by the Tetrel Elements and the Alkaline-Earth Metals. Dissertation No. 12546. ETH Zürich, Switzerland 1998.
5. Savin, A.; Nesper, R.; Wengert, S.; Fässler, T.: ELF: The Electron Localization Function. Angew. Chem. Int. Ed. 36 ( 1997) 1808-1832.

6. Sheldrick, G. M.: SHELXS-96. Program for the solution of crystal structures. University of Göttingen, Germany 1996.

7. Sheldrick, G. M.: SHELXL-96. Program for refining crystal structures. University of Göttingen. Germany 1996.

8. Hofmann, P.; Nesper, R.: COLTURE 3-D. Color Graphic Program. ETH Zürich, Switzerland 1995. 